\title{
Effect of Transition Elements on Dispersoid Formation and Elevated-Temperature Mechanical Properties in 6082 Aluminum Alloy
}

\author{
E.M. Elgallad*, K. Liu, Z. Zhang, X.-G. Chen \\ Department of Applied Science, University of Quebec at Chicoutimi, \\ Saguenay (QC), Canada G7H 2B1
}

\begin{abstract}
The effect of transition elements, specifically $\mathrm{Mn}, \mathrm{Cr}, \mathrm{V}$, and Mo, on dispersoid formation and mechanical properties in 6082 aluminum alloy was studied. The elevated-temperature mechanical properties were evaluated based on the compressive yield strength and creep resistance. The results indicated that the addition of $\mathrm{Mn}$ to the 6082 alloy resulted in the formation of a large number of the thermally stable $\alpha$-Al(MnFe)Si dispersoids, thereby significantly improving the elevated-temperature mechanical properties of the alloy. Subsequent additions of Cr, V, and Mo increased the amount of Mn-bearing intermetallic phases, which decreased the supersaturation levels of $\mathrm{Mn}$ and $\mathrm{Si}$ in the $\alpha$-Al, and consequently decreased the volume fraction of the dispersoids. The alloys containing $\mathrm{Cr}, \mathrm{V}$, and Mo exhibited similar yield strengths at $300{ }^{\circ} \mathrm{C}$ and higher yield strengths at room temperature compared to the alloy containing only $\mathrm{Mn}$. The size effect of the smaller dispersoids containing $\mathrm{Cr}, \mathrm{V}$, and Mo together with the solid-solution hardening of these elements could balance out the strength decrease resulting from the decreased volume fraction of the dispersoids. The additions of $\mathrm{Cr}$, V, and Mo significantly increased the creep resistance of the Mn-containing 6082 alloy. Vanadium induced the highest creep resistance followed by $\mathrm{Cr}$ and Mo. Solute atoms of these elements with low diffusivity in the aluminum matrix contributed significantly to increasing the creep resistance at $300{ }^{\circ} \mathrm{C}$.
\end{abstract}

Keywords: Al-Mg-Si 6082 alloy; transition elements; dispersoid strengthening; elevated-temperature mechanical properties; creep resistance.

*Corresponding author Tel.: +1 4185455011 \# 2558; Fax: +1 4185455012.

E-mail address: eelgalla@uqac.ca (E.M. Elgallad) 


\section{Introduction}

Improving the elevated-temperature mechanical properties of aluminum alloys is crucial for expanding the scope of the industrial applications of these alloys. Recent studies revealed that $\alpha$ Al(MnFe)Si dispersoids formed in Al-Mn-Mg 3004 and Al-Mg-Si 6082 alloys improved their elevatedtemperature mechanical properties, specifically yield strength and creep resistance at $300{ }^{\circ} \mathrm{C}$ [1-4]. These dispersoids were observed to precipitate during the homogenization of 3xxx and 6xxx alloys through the decomposition of the supersaturated $\alpha$-Al solid solution that was enriched by the dissolved Mn, Fe, and Si elements during the solidification [4-7]. They were reported to exhibit a cubic crystal structure [5] and to be partially coherent with the aluminum matrix, thereby improving the mechanical properties $[8,9]$.

The elevated-temperature mechanical properties of aluminum alloys could be further improved by adding transition and rare earth elements such as Mo, Er, Yb, and Gd [10-12]. These elements possess low diffusivities in $\mathrm{Al}$ and therefore effectively retard the coarsening of dispersoids and precipitates formed in these alloys, thereby increasing their elevated-temperature mechanical properties. The addition of transition elements such as Cr, V, and Mo to Al-Mn-Mg and Al-Si-Cu-Mg alloys was reported to produce a uniform distribution of dispersoids and decrease dispersoid free zones (DFZs) due to the opposite partitioning of the solute atoms of these elements and other elements with lower partition coefficients, namely, Mn, Fe, and Si, during solidification [10,13,14].

Al-Mg-Si 6082 alloys were reported to offer the highest strength in 6xxx alloys with an attractive balance of corrosion resistance, extrudability, formability, and machinability [15-17]. Therefore, these alloys are highly preferable over many other aluminum alloys for use in the automotive industry and high-load structural applications such as bridges, cranes, and trusses $[17,18]$. Some of these uses may involve high-temperature exposure, such as engineering structures in case of 
fire [19,20], which necessitates upgrading the elevated-temperature mechanical properties of 6082 alloys. However, these mechanical properties have been rarely investigated and developed systematically so far. Therefore, this study was conducted to enhance the elevated-temperature performance of 6082 alloy by introducing thermally stable dispersoids through the addition of transition elements, specifically $\mathrm{Mn}, \mathrm{Cr}, \mathrm{V}$, and Mo. The elevated-temperature performance of the experimental alloys was assessed by conducting compressive yield strength and creep tests at $300{ }^{\circ} \mathrm{C}$. Several characterization techniques, including optical microscopy, scanning and transmission electron microscopies, and electrical conductivity measurements, were used to characterize the as-cast and dispersoid microstructures.

\section{Experimental Procedures}

Six experimental alloys were prepared, including the base and five modified 6082 alloys. The modified alloys were intended to contain $1 \mathrm{wt} \% \mathrm{Mn}, 1 \mathrm{wt} \% \mathrm{Mn}+0.2 \mathrm{wt} \% \mathrm{Cr}, 1 \mathrm{wt} \% \mathrm{Mn}+0.2 \mathrm{wt} \% \mathrm{~V}$, $1 \mathrm{wt} \% \mathrm{Mn}+0.2 \mathrm{wt} \% \mathrm{Cr}+0.2 \mathrm{wt} \% \mathrm{~V}$, and $1 \mathrm{wt} \% \mathrm{Mn}+0.3 \mathrm{wt} \% \mathrm{Mo}$, respectively. The alloys were prepared using commercially pure $\mathrm{Al}$ (99.7 wt\%) and pure $\mathrm{Mg}$ (99.8 wt\%) as well as $\mathrm{Al}-25 \mathrm{wt} \% \mathrm{Fe}$, Al-50 wt\% Si, Al-25 wt\% Mn, Al-20 wt\% Cr, Al-5 wt\% V, and Al-10 wt\% Mo master alloys. Table 1 lists the actual chemical compositions of the alloys analyzed using an optical emission spectrometer.

For each alloy composition, approximately $3 \mathrm{~kg}$ of material was melted in a clay-graphite crucible using an electric resistance furnace. The melting temperature was maintained at $\sim 750{ }^{\circ} \mathrm{C}$ for $30 \mathrm{~min}$. The melt was then degassed for 15 min using pure and dry argon. After skimming the surface inclusions, the melt was poured into a permanent steel mold preheated to $250{ }^{\circ} \mathrm{C}$. The dimensions of the cast ingots obtained were $30 \mathrm{~mm} \times 40 \mathrm{~mm} \times 80 \mathrm{~mm}$. The homogenization treatment was conducted at $400{ }^{\circ} \mathrm{C}$ for $10 \mathrm{~h}$ with a heating ramp rate of $100{ }^{\circ} \mathrm{C} / \mathrm{h}$ followed by room-temperature water 
quenching. This homogenization treatment was specifically selected here based on previous studies on 6082-based alloys [4,21], which showed that the optimum precipitation of $\alpha-\mathrm{Al}(\mathrm{MnFe}) \mathrm{Si}$ dispersoids occurred in these alloys when homogenizing at $400{ }^{\circ} \mathrm{C}$ for 2 to $10 \mathrm{~h}$.

The microstructures of the as-cast and homogenized samples were examined using an optical microscope, a scanning electron microscope (SEM, Jeol JSM-6480LV) equipped with an energy dispersive X-ray spectrometer (EDS), and a transmission electron microscope (TEM, Jeol JEM-2100) operated at $200 \mathrm{kV}$. Polished samples were etched with $0.5 \% \mathrm{HF}$ for $25 \mathrm{~s}$ to clearly reveal the dispersoid zones (DZs) and dispersoid-free zones (DFZs). The samples used for the TEM observations were electropolished to perforation using a twinjet electropolisher in a solution of $1 / 3$ nitric acid and $2 / 3$ methanol at $-25^{\circ} \mathrm{C}$ and a potential difference of $12 \mathrm{~V}$.

An image analysis software, Clemex PE 4.0, was adopted to quantify the volume fraction of primary intermetallic phases and DFZs using optical microscope images and to measure the size and number density of dispersoids using TEM images. The volume fraction of dispersoids, $V_{\mathrm{v}}$, was calculated using the following equation [1]:

$$
V_{\mathrm{v}}=A_{\mathrm{A}} \frac{\mathrm{K} \overline{\mathrm{D}}}{\mathrm{K} \overline{\mathrm{D}}+\mathrm{t}}\left(1-A_{\mathrm{DFZ}}\right)
$$

where $\overline{\mathrm{D}}$ is the average equivalent diameter of dispersoids, which was calculated according to reference [1]; $A_{\mathrm{A}}$ is the area percentage of dispersoids obtained from the TEM image analysis; $A_{\mathrm{DFZ}}$ is the area percentage of DFZs obtained from the optical microscope image analysis; $\mathrm{K}$ is the average shape factor of dispersoids, which was considered equal to 0.45 ; and $t$ is the TEM foil thickness, which was measured using electron energy loss spectroscopy.

Electrical conductivity (EC) measurements were conducted on as-cast and homogenized samples to evaluate the evolution of the supersaturation and the decomposition of the $\alpha$-Al solid solution after homogenization treatment. The EC was measured using a Sigmascope SMP10 electrical 
conductivity system at room temperature in terms of percentage of the international annealed copper standard (\%IACS), and the average value of five measurements was recorded for each sample. Vickers microhardness measurements were performed on polished samples at room temperature using an NG1000 CCD microhardness tester with a load of $10 \mathrm{~g}$ and a dwell time of $15 \mathrm{~s}$. Twenty indentations were made on each sample, and the average hardness value was recorded. The indentations were made on the $\alpha$-Al matrix to determine the effect of dispersoids on the microhardness.

To study the elevated-temperature mechanical behavior of the alloys, all samples of compressive yield strength and creep tests were exposed to $300{ }^{\circ} \mathrm{C}$ for $100 \mathrm{~h}$ before testing in order to stabilize the microstructure. The compressive yield strengths at room temperature and $300{ }^{\circ} \mathrm{C}$ were obtained by conducting a compression test on a Gleeble 3800 thermomechanical machine using cylindrical specimens with a diameter of $10 \mathrm{~mm}$ and length of $15 \mathrm{~mm}$. For the compression test at 300 ${ }^{\circ} \mathrm{C}$, the specimen was heated to $300{ }^{\circ} \mathrm{C}$ at a heating rate of $2{ }^{\circ} \mathrm{C} / \mathrm{s}$ and held for $3 \mathrm{~min}$ before the test. The total deformation of the specimens was set to 0.2 and the strain rate was fixed at $10^{-3} \mathrm{~s}^{-1}$. For each alloy, three specimens were compressed and the average compressive yield strength at $0.2 \%$ offset strain was obtained. In addition, the compressive creep test was conducted at $300{ }^{\circ} \mathrm{C}$ for $100 \mathrm{~h}$ with a constant load of $\sim 70 \%$ of the compressive yield strength of the tested alloy. The creep specimens were the same as those used for the Gleeble compression test. For each alloy, three creep tests were conducted to confirm the reliability of the results.

\section{Results and discussion}

\subsection{As-cast microstructure}

The as-cast microstructures of the studied alloys are shown in Figs. 1a-f. For the base 6082 alloy (alloy A, Fig. 1a), the microstructure consisted of uniform, equiaxed $\alpha$-Al grains and interdendritic intermetallic phases including $\mathrm{Mg}_{2} \mathrm{Si}$ and platelet-like $\beta-\mathrm{Al}_{5} \mathrm{FeSi}$ intermetallics. The 
addition of Mn (alloy B, Fig. 1b) completely transformed the platelet-like $\beta$ - $\mathrm{Al}_{5} \mathrm{FeSi}$ intermetallic phase into the Chinese-script $\alpha-\mathrm{Al}_{15}(\mathrm{Fe}, \mathrm{Mn})_{3} \mathrm{Si}_{2}$ intermetallic phase. Other studies investigated and confirmed the modification of the $\beta-\mathrm{Al}_{5} \mathrm{FeSi}$ phase to the $\alpha-\mathrm{Al}_{15}(\mathrm{Fe}, \mathrm{Mn})_{3} \mathrm{Si}_{2}$ phase via the addition of $\mathrm{Mn}$ and other alloying elements such as Cr, V, Mo, and Sr [22-25]. When compared with alloy B, the subsequent addition of Cr or V (alloys C and D, Figs. 1c and d) seemingly increased the amount of the $\alpha$-Chinese script phase, which became also much coarser in the V-containing D alloy. The combined addition of $\mathrm{Cr}$ and $\mathrm{V}$ (alloy E, Fig. 1e) resulted in the formation of block-like Al-Mn-Cr-V sludge particles in addition to the $\mathrm{Mg}_{2} \mathrm{Si}$ and $\alpha$-Chinese script phases. The addition of Mo (alloy F, Fig. 1f) also promoted the formation of the $\alpha$-Chinese script phase, which appeared finer and well distributed within the interdendritic regions of $\alpha$-Al compared to the $\mathrm{Cr}$ - and $\mathrm{V}$-containing alloys. This can be attributed to the possible grain-refining effect of Mo in aluminum alloys [26-28], which could in turn enhance the distribution of the intermetallic phases within the $\alpha$-Al grains during solidification.

The intermetallic phases formed in all alloys were identified in the enlarged SEM images shown in Fig. 2 in conjunction with SEM-EDS analysis. Table 2 lists the chemical compositions of the $\alpha$ Chinese script phases formed in alloys B to F. Each composition represents the average of twenty EDS measurements conducted on phase particles obtained from different micro-fields. As Table 2 shows, the $\alpha$-Chinese script phases formed in alloys C, D, E, and F contained $\mathrm{Cr}, \mathrm{V}, \mathrm{Cr}+\mathrm{V}$, and Mo, respectively. Furthermore, the levels of $\mathrm{Mn}, \mathrm{Si}$, and $\mathrm{Fe}$ increased at the expense of $\mathrm{Al}$ in these phases when compared with the $\alpha$-Chinese script phase formed in alloy B. For the Al-Mn-Cr-V sludge particles formed in alloy E, the approximate composition was $78.8 \mathrm{wt} \% \mathrm{Al}, 10.5 \mathrm{wt} \% \mathrm{Mn}, 4.3 \mathrm{wt} \% \mathrm{Cr}$, and $6.4 \mathrm{wt} \% \mathrm{~V}$. The volume fractions of Mn-bearing intermetallic phases were also quantified for alloys B to F. Twenty micro-fields were analyzed per alloy and the average phase volume fraction was obtained. The results are listed in Table 3, which reveal that when compared with alloy B, the volume fraction of the $\alpha$-Chinese script phase was increased by 16.2, 13.6, 22.4, and 18.4\% in alloys C, D, E, 
and F, respectively. This is because Cr, V and Mo possess the same BCC crystal structure of Mn and Fe with comparable atomic radii and they can, therefore, substitute for $\mathrm{Mn}$ and Fe whether in the $\alpha-\mathrm{Al}$ solid solution or in the $\alpha-\mathrm{Al}_{15}(\mathrm{Fe}, \mathrm{Mn})_{3} \mathrm{Si}_{2}$ intermetallic phase. And since $\mathrm{Mn}$ and Fe maintained their same levels after adding these elements, the volume fraction of the $\alpha-\mathrm{Al}_{15}(\mathrm{Fe}, \mathrm{Mn})_{3} \mathrm{Si}_{2}$ intermetallic phase increased.

Given the volume fractions and the compositions of the $\alpha$-Chinese script phases formed in alloys B to F, the consumptions of alloying elements in these phases and consequently their available supersaturation levels in the $\alpha$-Al solid solutions of these alloys could be estimated (Table 4). It can be deduced that, when compared with the Mn-containing B alloy, the consumptions of Mn, Si, and Fe in the $\alpha$-Chinese script phase were increased in the C, D, E, and F alloys; as, for instance, these consumptions were increased by 28.2, 43.4, 60.3, and 26.7\% for Mn, and 45.0, 42.4, 72.1, and 42.1\% for Si in these latter alloys, respectively. Therefore, the supersaturation levels of Mn, Si, and Fe were decreased in the $\alpha$-Al solid solutions of alloys C, D, E, and F compared with alloy B, while these solid solutions were enriched with $\mathrm{Cr}, \mathrm{V}, \mathrm{Cr}$ and $\mathrm{V}$, and Mo, respectively. The supersaturation levels of Si, $\mathrm{Mn}, \mathrm{Cr}, \mathrm{V}$, and Mo in the Al matrix of alloys B to F were also verified inside the dendrite cells using electron probe microanalysis in conjunction with wavelength-dispersive X-ray spectrometry (EPMAWDX). The average levels of these elements are listed in Table 5, which further confirm the decrease in the supersaturation levels of $\mathrm{Mn}$ and $\mathrm{Si}$ and the enrichment of $\mathrm{Cr}, \mathrm{V}$, and Mo solutes in alloys $\mathrm{C}$ to F. The measured Cr, V, and Mo levels were observed to be higher than the calculated ones (Table 5 vs. Table 4), which is attributed to the solute segregation in the Al dendrites because the partition coefficients of $\mathrm{Cr}, \mathrm{V}$, and Mo are larger than 1. This segregation would be reduced after homogenization at $400{ }^{\circ} \mathrm{C}$ for $10 \mathrm{~h}$. Further increases in the homogenization temperature and time can more effectively reduce the microsegregation, but at the same time would lead to deterioration of the characteristics of dispersoids in terms of their size and volume fraction, as confirmed by previous 
studies [4,6,21,29]. In brief, the addition of transition elements (Cr, V, and Mo) decreased the supersaturation levels of $\mathrm{Mn}, \mathrm{Si}$, and $\mathrm{Fe}$ in the $\alpha$-Al solid solutions of alloys $\mathrm{C}$ to $\mathrm{F}$ by promoting the formation of the $\alpha$-Chinese script intermetallic phase, but enriched these solid solutions to different extents.

\subsection{Homogenized microstructure}

No dispersoids were observed in the base A alloy (Mn-free alloy) after homogenization. In contrast, a large number of dispersoids were formed in alloys B to F after homogenization, building the DZs, as shown for some of these alloys in Figs. 3a to d. The DFZs, which were outside the DZs, were generally formed around the Mn-containing intermetallic phases owing to the depletion of Mn near these phases [30,31]. The volume fractions of the DFZs obtained by the quantitative image analysis are listed in Table 6. It can be seen that alloys $\mathrm{C}$ to F, which previously exhibited higher volume fractions of the Mn-containing intermetallic phases, also exhibited higher volume fractions of DFZs compared with alloy B.

TEM bright-field images revealed the features of nanosize dispersoids formed in alloys B to F, as shown in Figs. 4a to e. A $[001]_{\alpha}$ zone axis recorded selected-area electron diffraction pattern (SAEDP) corresponding to Fig. 4a is given in Fig. 4f. Table 6 lists the average equivalent diameter and the volume fraction of the dispersoids, as calculated using Eq. (1) based on the image analysis of five TEM images. The SAEDP shown in Fig. 4f displays faint spots at $\{110\}_{\mathrm{Al}}$ positions (indicated by dotted arrows), which is a characteristic feature of $\alpha$-Al(MnFe)Si dispersoids [1,5,29]. This feature was similarly observed in the SAEDPs of alloys C to F. The chemical compositions of the dispersoids were analyzed using TEM-EDS analysis for further confirmation. The resulting TEM-EDS spectra are shown

in Fig. 5. The chemical composition of the dispersoids in alloy B was found matching the reported chemical composition of the $\alpha$-Al(MnFe)Si dispersoids, namely $\mathrm{Al}_{12-20}(\mathrm{MnFe})_{3} \mathrm{Si}_{2}[1,5]$. For alloys C, 
D, E, and F, the chemical compositions of the dispersoids were also comparable to this composition, but with the presence of $\mathrm{Cr}, \mathrm{V}, \mathrm{Cr}$ and $\mathrm{V}$, and Mo, respectively. The morphology of the dispersoids combined between the plate-like and cubic morphologies (indicated by the solid and dotted arrows, respectively, in Figs. 4a to e), agreeing well with the reported morphologies of the $\alpha-\mathrm{Al}(\mathrm{MnFe}) \mathrm{Si}$ dispersoids [1,3,5]. It is also interesting to observe the typical alignment of the dispersoids along $<100>_{\mathrm{Al}}$ directions in Fig. 4d, alloy E. It is evident that the dispersoids preferentially precipitated in the locations, in which $\mathrm{Mg}_{2} \mathrm{Si}$ precipitates previously precipitated and then dissolved during the heating stage of homogenization, creating potential nucleation sites for dispersoids [3,32].

The results shown in Fig. 4 and Table 6 indicate that the addition of Mn to the 6082 alloy (alloy B) resulted in the precipitation of a high volume fraction (1.85\%) of $\alpha$-Al(MnFe)Si dispersoids. However, with the subsequent additions of $\mathrm{Cr}, \mathrm{V}$, and $\mathrm{Mo}$, the volume fraction of the dispersoids decreased to $1.22,1.32,1.07$, and $1.24 \%$ in alloys $\mathrm{C}$ to $\mathrm{F}$, respectively. This can be ascribed to the decrease in the supersaturation levels of $\mathrm{Mn}$ and $\mathrm{Si}$ in the matrix, as explained in the previous section, which would in turn decrease the driving force for the precipitation of the dispersoids. On the other hand, the involvement of Cr, V, and Mo in the formation of the dispersoids (Fig. 5) could decrease their growth kinetics, taking into consideration the extremely low diffusivities of these elements in $\mathrm{Al}$ (1.29 $\times 10^{-21}, 4.85 \times 10^{-24}$ and $5.52 \times 10^{-23} \mathrm{~m}^{2} \mathrm{~s}^{-1}$ at $400{ }^{\circ} \mathrm{C}$, respectively [33]). This explains why the dispersoids were relatively smaller in alloys C to F compared with alloy B, and also why alloy E, which contained both $\mathrm{Cr}$ and $\mathrm{V}$, particularly exhibited the smallest dispersoids among the other alloys.

\subsection{Evolution of the a-Al solid solution}

The as-cast and homogenized microstructures of all six alloys were compared in terms of the evolution of the supersaturation and decomposition of the $\alpha$-Al solid solution using EC measurements, 
and the results are shown in Fig. 6. In the as-cast condition, the solid solution was enriched by solute atoms, which could effectively scatter the electrons and consequently decrease the EC. However, after homogenization, the solid solution was mostly decomposed into either $\mathrm{Mg}_{2} \mathrm{Si}$ precipitates or $\alpha$ $\mathrm{Al}(\mathrm{MnFe}) \mathrm{Si}$ dispersoids, which were less effective than solute atoms in scattering the electrons and consequently increased the EC. As Fig. 6 shows, in the as-cast condition, the addition of Mn abruptly decreased the EC from $47.8 \%$ IACS in alloy A to $28.2 \%$ IACS in alloy B. This reveals the high level of Mn supersaturation in the solid solution of alloy B that was attained after solidification. In addition, the difference between the ECs in the homogenized and as-cast conditions was remarkably higher for alloy B than for alloy A (17.3\% IACS vs. 5.2\% IACS). This is because a high volume fraction of $\alpha$ $\mathrm{Al}(\mathrm{MnFe}) \mathrm{Si}$ dispersoids precipitated out of the solid solution after homogenization in alloy $\mathrm{B}$, while only a small amount of $\mathrm{Mg}_{2} \mathrm{Si}$ particles precipitated out in alloy A.

In the as-cast condition, alloys C to F exhibited only slightly lower ECs (27.4, 26.3, 27.5, and 26.5\% IACS, respectively) than alloy B (28.2\% IACS). This can be explained by the two opposite effects of $\mathrm{Cr}, \mathrm{V}$, and Mo additions, namely the depletion of $\mathrm{Mn}$ and the enrichment of the solute atoms of Cr, V, and Mo. However, in the homogenized condition, the ECs of alloys C to F (39.9, 38.6, 37.7, and 36.5\% IACS, respectively) were apparently lower than that of alloy B (45.5\% IACS). This reveals that the solid solutions of the former alloys were still enriched with $\mathrm{Cr}, \mathrm{V}$, and Mo solutes after the precipitation of the dispersoids.

The remaining supersaturation levels of $\mathrm{Cr}, \mathrm{V}$, and Mo in the $\alpha$-Al solid solutions of alloys $\mathrm{C}$ to F after homogenization were approximately calculated to further confirm the EC results. Because Cr, $\mathrm{V}$, and Mo also participated in the precipitation of dispersoids in alloys $\mathrm{C}$ to $\mathrm{F}$, their consumptions in these dispersoids were initially determined. Based on the TEM-EDS analysis (Fig. 5), maximum levels of $1.0 \mathrm{wt} \% \mathrm{Cr}, 0.4 \mathrm{wt} \% \mathrm{~V}, 0.8 \mathrm{wt} \% \mathrm{Cr}+0.5 \mathrm{wt} \% \mathrm{~V}$, and $0.9 \mathrm{wt} \%$ Mo were detected in the dispersoids formed in alloys $\mathrm{C}$ to $\mathrm{F}$, respectively. These low levels can be explained in terms of the very slow 
solid-state diffusions of $\mathrm{Cr}, \mathrm{V}$, and $\mathrm{Mo}$ in $\mathrm{Al}$ which made their substitutions for $\mathrm{Mn}, \mathrm{Si}$, and $\mathrm{Fe}$ in the dispersoids very limited during the homogenization. Increasing the homogenization temperature above $400{ }^{\circ} \mathrm{C}$ could promote the contribution of $\mathrm{Cr}, \mathrm{V}$ and Mo to the $\alpha$-Al(MnFe)Si dispersoids, but, on the other hand, would coarsen these dispersoids [4,21]. Given these levels and the volume fractions of the dispersoids formed in alloys C to F (Table 6), it was calculated that $0.016 \mathrm{wt} \% \mathrm{Cr}, 0.007 \mathrm{wt} \% \mathrm{~V}, 0.011$ $\mathrm{wt} \% \mathrm{Cr}+0.007 \mathrm{wt} \% \mathrm{~V}$, and $0.015 \mathrm{wt} \%$ Mo were consumed in these dispersoids, respectively. Based on these consumptions and the remaining supersaturation levels of $\mathrm{Cr}, \mathrm{V}$, and $\mathrm{Mo}$ in the as-cast condition (Table 4), it was found that approximately $0.117 \mathrm{wt} \% \mathrm{Cr}, 0.226 \mathrm{wt} \% \mathrm{~V}, 0.144 \mathrm{wt} \% \mathrm{Cr}+$ $0.216 \mathrm{wt} \% \mathrm{~V}$, and $0.235 \mathrm{wt} \%$ Mo remained in the solid solutions of alloys C to F, respectively. When comparing these levels with the original contents of $\mathrm{Cr}, \mathrm{V}$, and Mo (Table 1), it is obvious that large amounts of their solutes still enriched the solid solutions of alloys C to F even after the precipitation of the dispersoids during the homogenization.

\subsection{Mechanical properties}

Fig. 7 shows the microhardness values of the alloys after homogenization. The microhardness increased from $36.1 \mathrm{HV}$ in alloy A to $68 \mathrm{HV}$ in alloy B, representing a remarkable increase of $88 \%$. This increase is attributed to the strengthening effect of the $\alpha-\mathrm{Al}(\mathrm{MnFe}) \mathrm{Si}$ dispersoids, which were precipitated out of the solid solution in alloy B during homogenization. On the other hand, the microstructure of alloy A contained a small amount of non-coherent equilibrium $\beta-\mathrm{Mg}_{2} \mathrm{Si}$ particles (not shown here), which produced virtually no strengthening effect on the alloy. The alloys containing Cr, V, and Mo, alloys C to F, exhibited higher microhardness values than alloy B (74, 77, 74, and $70 \mathrm{HV}$ vs. $68 \mathrm{HV}$ ), although they contained lower volume fractions of the dispersoids relative to alloy $\mathrm{B}$ (Table 4). 
Fig. 7 also shows the compressive yield strengths at both room temperature and $300{ }^{\circ} \mathrm{C}$, considering that the alloy samples were stabilized at $300^{\circ} \mathrm{C}$ for $100 \mathrm{~h}$ before testing. The yield strength (YS) increased from 50.4 MPa in alloy A to 106.8 MPa in alloy B at room temperature, and from 24.4 to $68.9 \mathrm{MPa}$ at $300{ }^{\circ} \mathrm{C}$. These represent exceptional increases of 112 and $182 \%$, respectively, owing to the strengthening effect of a large number of $\alpha-\mathrm{Al}(\mathrm{Mn}, \mathrm{Fe}) \mathrm{Si}$ dispersoids. In addition, the increase in the YS at $300{ }^{\circ} \mathrm{C}$ was remarkably higher than that at room temperature (182 vs. 112\%), revealing the potential of the $\alpha-\mathrm{Al}(\mathrm{Mn}, \mathrm{Fe}) \mathrm{Si}$ dispersoids to significantly improve the elevated-temperature mechanical properties. These increases also reflect the superior thermal stability of these dispersoids at elevated temperatures. Alloys C to F displayed moderately higher YSs at room temperature compared with alloy $\mathrm{B}$, which is consistent with the microhardness measurements. It is worthy of notice that the YSs of alloys B to $\mathrm{F}$ at $30{ }^{\circ} \mathrm{C}$ were comparable (68.9, 70.5, 72.0, 68.7, and 67.6 MPa, respectively). This indicates that the decrease in the strength expected from the decreased volume fraction of dispersoids in the alloys containing $\mathrm{Cr}, \mathrm{V}$ and Mo (alloys $\mathrm{C}$ to $\mathrm{F}$ ) could be compensated by the strengthening effect of the smaller dispersoids and the solid solution hardening of $\mathrm{Cr}$, $\mathrm{V}$, and Mo when compared with alloy B.

The contribution of the dispersoids to the YS, $\sigma_{\mathrm{D}}$, can be generally explained based on the Orowan by-passing mechanism and can, therefore, be estimated using the Ashby-Orowan equation [34]:

$$
\sigma_{\mathrm{D}}=\frac{0.84 M G b}{2 \pi(1-v)^{1 / 2} \lambda} \ln \frac{r}{b}
$$

where $M$ is the Taylor factor, $b$ is the Burgers vector of dislocations in Al, and $v$ is the Poisson's ratio. The values of these parameters are $2,0.286 \mathrm{~nm}$, and 0.33 , respectively [8]. The shear modulus of the $\mathrm{Al}$ 
matrix, $G$, equals $27.4 \mathrm{GPa}$ at room temperature and $21.1 \mathrm{GPa}$ at $300{ }^{\circ} \mathrm{C}[8,35]$. The interspacing of dispersoids, $\lambda$, is given by:

$$
\lambda=r\left(\frac{2 \pi}{3 f}\right)^{1 / 2}
$$

where $r$ and $f$ are the average radius and the volume fraction of dispersoids, respectively. By substituting the measured data (Table 4) into Eqs. 2 and 3, the contributions of the dispersoids to the YSs of alloys B to F were calculated as shown in Table 7. The measured increments in the YSs of these alloys relative to the base A alloy are also listed in Table 7.

In general, the measured YS increment consists mainly of the contributions of both dispersoid strengthening and solid solution hardening [36]. In alloy B, the calculated YS contribution from the dispersoids represents approximately 85\% of the measured YS increment at room temperature and 300 ${ }^{\circ} \mathrm{C}$. The remainder of the measured YS increment was caused by the solid solution strengthening of $\mathrm{Mg}$ and Mn solutes remaining in the matrix. The calculated YS contributions from the dispersoids in alloys C to $\mathrm{F}$ were only slightly lower than those in alloy $\mathrm{B}$, despite the lower volume fractions of the dispersoids in these alloys compared with alloy B. This is because the dispersoids in alloys $\mathrm{C}$ to $\mathrm{F}$ were relatively smaller than those in alloy B, bearing in mind that, according to Eqs. 2 and 3, the strength induced by the nanoparticles is more affected by their size than by their volume fraction. It is interesting to note in Table 7 that the calculated YS contributions from the dispersoids in alloys $\mathrm{C}$ to $\mathrm{F}$, were close to each other whether at room temperature or $300{ }^{\circ} \mathrm{C}$, representing approximately 70 to $80 \%$ of the measured YS increments. Similarly, the remainders of the measured YS increments were caused by the solid solution strengthening of $\mathrm{Cr}, \mathrm{V}$, and $\mathrm{Mo}$ in addition to $\mathrm{Mg}$ and $\mathrm{Mn}$ solutes remaining in the matrix. The measured YS increments in alloys $\mathrm{C}$ to $\mathrm{F}$ were similar to that in alloy $\mathrm{B}$ at $300{ }^{\circ} \mathrm{C}$ and 
moderately exceeded it at room temperature, which further confirms the solid solution strengthening of the solute atoms of $\mathrm{Cr}, \mathrm{V}$, and Mo in alloys $\mathrm{C}$ to $\mathrm{F}$.

\subsection{Creep resistance}

For high-temperature structural applications, creep resistance is one of the most important considerations for alloy design and development. Compressive creep test at $300{ }^{\circ} \mathrm{C}$ was performed for all six alloys after homogenization and stabilization at $300{ }^{\circ} \mathrm{C}$ for $100 \mathrm{~h}$. The creep load was taken to be approximately equal to 0.7 of the YS at $300{ }^{\circ} \mathrm{C}$. Owing to the large difference in the YS between the base A alloy and the B to F alloys, the creep test was conducted at constant loads of $18 \mathrm{MPa}$ for the A alloy and $50 \mathrm{MPa}$ for the other alloys. The creep curves of all alloys are shown in Fig. 8. As Fig. 8a shows, the base A alloy (dispersoid-free alloy) exhibited an extremely low creep resistance, attaining the strain limit of the creep machine (0.39) after only $25 \mathrm{~h}$. At this time, alloy B attained a creep strain of 0.025 , which was less than that of alloy A by approximately $94 \%$ even though the creep load applied to the former was 2.8 times that applied to the latter. Considering the minimum creep rate, the creep resistance of alloy A was several orders lower than that of alloy B. This reveals the superior creep resistance of alloy B which is attributed to the significant effect of dispersoids on the dislocation mobility, since the creep mechanism under such test conditions was considered to be mainly controlled by the glide and climb of dislocations [37]. Fig. 9 shows a bright-field TEM image obtained from the crept sample of alloy B, where interactions between dislocations and dispersoids occurred during creeping can be observed (indicated by dotted arrows).

Subsequent additions of $\mathrm{Cr}, \mathrm{V}$, and Mo further significantly increased the creep resistance by decreasing the creep strain after $100 \mathrm{~h}$ from 0.093 in alloy B to $0.017,0.010,0.016$, and 0.048 in alloys C, D, E, and F (Fig. 8b), respectively, representing decreases in the creep strain of approximately 82, 
89, 83 , and $48 \%$ for alloys C to F, respectively. In addition, the minimum creep rates of the alloys were calculated based on the creep data in the steady state (Fig. 8b). The minimum creep rates were $2.5 \times$ $10^{-7} \mathrm{~s}^{-1}, 3.6 \times 10^{-8} \mathrm{~s}^{-1}, 2.2 \times 10^{-8} \mathrm{~s}^{-1}, 3.9 \times 10^{-8} \mathrm{~s}^{-1}$, and $1.1 \times 10^{-7} \mathrm{~s}^{-1}$ for alloys B to F, respectively. The change tendency of the minimum creep rate from one alloy to another is consistent with the creep strain change; therefore, the creep resistances of the alloys containing dispersoids can be ranked in the following order: $\mathrm{D}>\mathrm{E}>\mathrm{C}>\mathrm{F}>\mathrm{B}$.

As mentioned in Section 3.2 (Table 6), the dispersoids formed in alloys $\mathrm{C}$ to $\mathrm{F}$ were smaller than those formed in alloy B and they could, therefore, be more effective in hindering dislocation movements during creeping, increasing the creep resistance to a certain extent in the former four alloys. However, taking into consideration the decreased volume fraction of the dispersoids due to the additions of $\mathrm{Cr}, \mathrm{V}$, and Mo, the significant increases in the creep resistances of the alloys bearing these elements could not be primarily attributed to the size effect of the dispersoids formed in these alloys. The solute atoms of Cr, V, and Mo remaining in the aluminum matrix (see Section 3.3) could play an important role in improving the creep resistance. Studies by Sherby et al. $[38,39]$ proposed a creep mechanism to explain the high creep resistance of aluminum alloys containing traces of $\mathrm{Fe}, \mathrm{Mn}$, and $\mathrm{Ti}$, based on a dislocation climb model in subgrain boundaries involving solute atom diffusion. Their results revealed that 1 ) the creep process was strongly controlled by the rate of the solute diffusion in aluminum, and 2) the activation energy for creep of aluminum alloys was equal to the activation energy for the solute diffusion in aluminum. In other words, aluminum alloys containing solutes that diffused slower than aluminum exhibited slower creep rates and higher activation energies for creep than pure aluminum. The activation energies for the diffusion of $\mathrm{V}, \mathrm{Cr}, \mathrm{Mo}$, and $\mathrm{Mn}$ in $\mathrm{Al}$ were reported to be equal to 303, 282, 250, and $208 \mathrm{KJ}_{\mathrm{mol}}{ }^{-1}$, respectively [33]. In this study, V induced the highest creep resistance followed by $\mathrm{Cr}$ and Mo, while the Mn-containing B alloy had the lowest creep resistance. This agrees remarkably well with the order of the activation energies for the diffusion of $\mathrm{V}, \mathrm{Cr}$, Mo, 
and $\mathrm{Mn}$ in Al. Therefore, it is reasonable to adopt Sherby's model to explain the important role of slowdiffusion solute atoms of $\mathrm{V}, \mathrm{Cr}$, and Mo in increasing the creep resistance of the 6082 alloy.

\section{Conclusions}

1. The addition of $1 \%$ Mn to 6082 aluminum alloy resulted in the formation of a large number of thermally stable $\alpha-\mathrm{Al}(\mathrm{MnFe}) \mathrm{Si}$ dispersoids in the microstructure after homogenization, which in turn remarkably improved the elevated-temperature mechanical properties of the alloy. The compressive yield strength at $300{ }^{\circ} \mathrm{C}$ was increased by $182 \%$ and the creep resistance was increased by several orders.

2. Subsequent additions of $\mathrm{Cr}, \mathrm{V}$, and Mo increased the amount of Mn-bearing intermetallic phases, which decreased the supersaturation levels of $\mathrm{Mn}$ and $\mathrm{Si}$ in the $\alpha$-Al matrix, and consequently decreased the volume fraction of the dispersoids.

3. The alloys containing $\mathrm{Cr}, \mathrm{V}$, and Mo exhibited moderately higher yield strengths at room temperature and similar yield strengths at $300{ }^{\circ} \mathrm{C}$ relative to the alloy containing only $\mathrm{Mn}$, indicating that the strength decrease expected from the decreased volume fraction of the dispersoids could be compensated by the strengthening effect of the smaller dispersoids and the solid solution hardening of Cr, V, and Mo.

4. The additions of $\mathrm{Cr}, \mathrm{V}$, and Mo significantly increased the creep resistance of the Mn-containing 6082 alloy. Vanadium induced the highest creep resistance followed by $\mathrm{Cr}$ and Mo. In addition to the size effect of the smaller dispersoids containing $\mathrm{Cr}, \mathrm{V}$, and Mo, solute atoms of these elements with low diffusivity in the aluminum matrix contributed significantly to increasing the creep resistance. 


\section{Acknowledgments}

The authors would like to acknowledge the financial support of the Natural Sciences and Engineering Research Council of Canada (NSERC) under the Grant No. CRDPJ 514651-17 and Rio Tinto Aluminum through the Research Chair in the Metallurgy of Aluminum Transformation at University of Quebec at Chicoutimi.

\section{References}

[1] K. Liu and X.-G. Chen, Development of Al-Mn-Mg 3004 alloy for applications at elevated temperature via dispersoid strengthening, Mater. Des. 84 (2015), pp. 340-350.

[2] K. Liu and X.-G. Chen, Evolution of intermetallics, dispersoids, and elevated temperature properties at various Fe contents in Al-Mn-Mg 3004 alloys, Metall. Mater. Trans. B 47 (2016), pp. 3291-3300.

[3] Z. Li, Z. Zhang, and X.-G. Chen, Microstructure, elevated-temperature mechanical properties and creep resistance of dispersoid-strengthened Al-Mn-Mg 3xxx alloys with varying $\mathrm{Mg}$ and Si contents, Mater. Sci. Eng. A 708 (2017), pp. 383-394.

[4] C. Li, K. Liu, and X.-G. Chen, Improvement of elevated-temperature strength and recrystallization resistance via Mn-containing dispersoid strengthening in Al-Mg-Si 6082 alloys, J. Mater. Sci. Technol. 39 (2020), pp. 135-143.

[5] Y.J. Li and L. Arnberg, Quantitative study on the precipitation behavior of dispersoids in DCcast AA3003 alloy during heating and homogenization, Acta Mater. 51 (2003), pp. 3415-3428.

[6] Hsin-Wen Huang and Bin-Lung Ou, Evolution of precipitation during different homogenization treatments in a 3003 aluminum alloy, Mater. Des. 30 (2009), pp. 2685-2692. 
[7] Astrid Marie F. Muggerud, Eva Anne Mørtsell, Yanjun Li, and Randi Holmestad, Dispersoid strengthening in AA3xxx alloys with varying $M n$ and Si content during annealing at low temperatures, Mater. Sci. Eng. A 567 (2013), pp. 21-28.

[8] Y.J. Li, A.M.F. Muggerud, A. Olsen, and T. Furu, Precipitation of partially coherent $\alpha$ Al(Mn,Fe)Si dispersoids and their strengthening effect in AA 3003 alloy, Acta Mater. 60 (2012), pp. 1004-1014.

[9] Y.J. Li and L. Arnberg, Precipitation of dispersoids in DC-cast AA3103 alloy during heat treatment, in Essential Readings in Light Metals, J.F. Grandfield and D.G. Eskin, eds., Springer, Cham, 2016, pp. 1021-1027.

[10] K. Liu, H. Ma, and X.-G. Chen, Enhanced elevated-temperature properties via Mo addition in Al-Mn-Mg 3004 alloy, J. Alloys Compd. 694 (2017), pp. 354-365.

[11] Christopher Booth-Morrison, David C. Dunand, and David N. Seidman, Coarsening resistance at $400{ }^{\circ} \mathrm{C}$ of precipitation-strengthened Al-Zr-Sc-Er alloys, Acta Mater. 59 (2011), pp. 7029-7042.

[12] Marsha E. van Dalen, David C. Dunand, and David N. Seidman, Nanoscale precipitation and mechanical properties of Al-0.06 at.\% Sc alloys microalloyed with Yb or Gd, J. Mater. Sci. 41 (2006), pp. 7814-7823.

[13] A.R. Farkoosh, X.-G. Chen, and M. Pekguleryuz, Interaction between molybdenum and manganese to form effective dispersoids in an Al-Si-Cu-Mg alloy and their influence on creep resistance, Mater. Sci. Eng. A 627 (2015), pp. 127-138.

[14] A.R. Farkoosh, X.-G. Chen, and M. Pekguleryuz, Dispersoid strengthening of a high temperature Al-Si-Cu-Mg alloy via Mo addition, Mater. Sci. Eng. A 620 (2015), pp. 181-189.

[15] N. Bayat and T. Carlberg, Influence of heat treatment on the surface structure of 6082 Al alloys, Metall. Mater. Trans. A 48 (2017), pp. 5085-5094. 
[16] L. Calabrese, E. Proverbio, G. Di Bella, G. Galtieri, and C. Borsellino, Failure behaviour of SPR joints after salt spray test, Eng. Struct. 82 (2015), pp. 33-43.

[17] J.H. Li, A. Wimmer, G. Dehm, and P. Schumacher, Intermetallic phase selection during homogenization for AA6082 alloy, Philos. Mag. 94 (2014), pp. 830-846.

[18] M. Cabibbo, E. Evangelista, and M. Vedani, Influence of severe plastic deformations on secondary phase precipitation in a 6082 Al-Mg-Si alloy, Metall. Mater. Trans. A 36 (2005), pp. 1353-1364.

[19] E.J. Fogle, B.Y. Lattimer, S. Feih, E. Kandare, A.P. Mouritz, and S.W. Case, Compression load failure of aluminum plates due to fire, Eng. Struct. 34 (2012), pp. 155-162.

[20] Y. Liu, H. Liu, and Z. Chen, Post-fire mechanical properties of aluminum alloy 6082-T6, Constr. Build. Mater. 196 (2019), pp. 256-266.

[21] C. Li, K. Liu, N. Parson, and X.-G. Chen, The effect of heat treatments on precipitation behavior of dispersoids in Al-Mg-Si-Mn alloy, ICAA16, Montreal, QC, 2018.

[22] S.G. Shabestari, The effect of iron and manganese on the formation of intermetallic compounds in aluminum-silicon alloys, Mater. Sci. Eng. A 383 (2004), pp. 289-298.

[23] Giulio Timelli and Franco Bonollo, The influence of Cr content on the microstructure and mechanical properties of $\mathrm{AlSi}_{9} \mathrm{Cu}(\mathrm{Fe})$ die-casting alloys, Mater. Sci. Eng. A 528 (2010), pp. 273-282.

[24] T.O. Mbuya, B.O. Odera, and S.P. Ng'ang'a, Influence of iron on castability and properties of aluminium silicon alloys: literature review, Int. J. Cast Met. Res. 16 (2003), pp. 451-465.

[25] L. Anantha Narayanan, F.H. Samuel, and J.E. Gruzleski, Crystallization behavior of ironcontaining intermetallic compounds in 319 aluminum alloy, Metall. Mater. Trans. A 25 (1994), pp. 1761-1773.

[26] L.F. Mondolfo, Aluminum Alloys: Structure and Properties, Butterworth, London, 1976. 
[27] F. A. Crossley and L. F. Mondolfo, Mechanism of grain refinement in aluminum alloys, JOM 3 (1951), pp. 1143-1148.

[28] B.D. Warr, G.W. Delamore, and R.W. Smith, The Grain refinement of high-purity aluminum by aluminum-transition metal alloys, Metall. Mater. Trans. B 6 (1975), pp. 625-629.

[29] G.S. Wang, K. Liu, and S.L. Wang, Evolution of elevated-temperature strength and creep resistance during multi-step heat treatments in Al-Mn-Mg alloy, Materials 11 (2018), pp. 1-14.

[30] Rajeev G. Kamat, AA3104 can-body stock ingot: Characterization and homogenization, JOM 48 (1996), pp. 34-38.

[31] K. Liu and X.-G. Chen, Evolution of microstructure and elevated-temperature properties with Mn addition in Al-Mn-Mg alloys, J. Mater. Res. 32 (2017), pp. 2585-2593.

[32] L. Lodgaard and N. Ryum, Precipitation of dispersoids containing $\mathrm{Mn}$ and:or Cr in Al-Mg-Si alloys, Mater. Sci. Eng. A 283 (2000), pp. 144-152.

[33] Keith E. Knipling, David C. Dunand, and David N. Seidman, Criteria for developing castable, creep-resistant aluminum-based alloys - A review, Int. J. Mater. Res. 97 (2006), pp. 246-265.

[34] M.F. Ashby, Oxide dispersion strengthening, AIME Conference Proceedings, New York Meeting Society, New York, 1966.

[35] J. Qin, Z. Zhang, and X.-G. Chen, Mechanical properties and strengthening mechanisms of Al-15 Pct B4C composites with Sc and Zr at elevated temperatures, Metall. Mater. Trans. A 47 (2016), pp. 4694-4708.

[36] Z. Li, Z. Zhang, and X.-G. Chen, Improvement in the mechanical properties and creep resistance of Al-Mn-Mg 3004 alloy with Sc and Zr addition, Mater. Sci. Eng. A 729 (2018), pp. 196-207.

[37] G.E. Dieter, Mechanical Metallurgy, McGraw-Hill, New York , 1976.

[38] O. D. Sherby and O. A. Ruano, Rate-controlling processes in creep of subgrain containing aluminum materials, Mater. Sci. Eng. A 410-411 (2005), pp. 8-11. 
[39] O. D. Sherby, A. Goldberg, and O. A. Ruano, Solute-diffusion-controlled dislocation creep in pure aluminum containing 0.026 at.\% Fe, Philos. Mag. 84 (2004), pp. 2417-2434. 


\section{Tables}

Table 1. Chemical compositions of experimental alloys.

\begin{tabular}{ccccccccc}
\hline \multirow{2}{*}{ Alloy } & \multicolumn{7}{c}{ Elements (wt\%) } \\
\cline { 2 - 9 } & $\mathrm{Si}$ & $\mathrm{Fe}$ & $\mathrm{Mg}$ & $\mathrm{Mn}$ & $\mathrm{Cr}$ & $\mathrm{V}$ & $\mathrm{Mo}$ & $\mathrm{Al}$ \\
\hline $\mathrm{A}$ & 0.77 & 0.28 & 1.18 & 0.00 & 0.00 & 0.00 & 0.00 & Bal. \\
$\mathrm{B}$ & 0.82 & 0.29 & 1.16 & 1.04 & 0.00 & 0.00 & 0.00 & Bal. \\
$\mathrm{C}$ & 0.86 & 0.30 & 1.22 & 1.00 & 0.18 & 0.00 & 0.00 & Bal. \\
$\mathrm{D}$ & 0.82 & 0.30 & 1.15 & 1.04 & 0.00 & 0.25 & 0.00 & Bal. \\
$\mathrm{E}$ & 0.78 & 0.32 & 1.22 & 1.05 & 0.22 & 0.25 & 0.00 & Bal. \\
$\mathrm{F}$ & 0.77 & 0.31 & 1.16 & 1.01 & 0.00 & 0.00 & 0.30 & Bal. \\
\hline
\end{tabular}

Table 2. Average compositions of the $\alpha$-Chinese script intermetallics in alloys B to F.

\begin{tabular}{cccccccc}
\hline \multirow{2}{*}{ Alloy } & \multicolumn{7}{c}{ Elements in the $\alpha$-Chinese script intermetallics (wt\%) } \\
\cline { 2 - 8 } & $\mathrm{Al}$ & $\mathrm{Mn}$ & $\mathrm{Fe}$ & $\mathrm{Si}$ & $\mathrm{Cr}$ & $\mathrm{V}$ & $\mathrm{Mo}$ \\
\hline $\mathrm{B}$ & $75.4 \pm 0.4$ & $9.6 \pm 0.4$ & $8.0 \pm 0.9$ & $6.9 \pm 0.4$ & 0.0 & 0.0 & 0.0 \\
$\mathrm{C}$ & $71.3 \pm 0.5$ & $10.6 \pm 1.0$ & $8.2 \pm 0.4$ & $8.6 \pm 0.8$ & $1.3 \pm 0.2$ & 0.0 & 0.0 \\
$\mathrm{D}$ & $70.6 \pm 0.6$ & $12.1 \pm 0.9$ & $8.4 \pm 0.6$ & $8.6 \pm 0.4$ & 0.0 & $0.5 \pm 0.1$ & 0.0 \\
$\mathrm{E}$ & $66.9 \pm 0.8$ & $12.6 \pm 0.8$ & $8.2 \pm 0.2$ & $9.7 \pm 0.7$ & $1.7 \pm 0.3$ & $0.7 \pm 0.2$ & 0.0 \\
$\mathrm{~F}$ & $71.8 \pm 1.0$ & $10.3 \pm 0.8$ & $8.2 \pm 0.8$ & $8.3 \pm 0.6$ & 0.0 & 0.0 & $1.4 \pm 0.3$ \\
\hline
\end{tabular}

Table 3. Volume fractions of Mn-bearing intermetallic phases.

\begin{tabular}{rrccccc}
\hline \multicolumn{2}{c}{ Alloy } & B & C & D & E & F \\
\hline $\begin{array}{r}\text { Volume } \\
\text { script phase }\end{array}$ & $2.37 \pm 0.37$ & $2.76 \pm 0.28$ & $2.70 \pm 0.23$ & $2.90 \pm 0.24$ & $2.81 \pm 0.15$ \\
sraction (\%) & $\begin{array}{r}\text { Sludge } \\
\text { particles }\end{array}$ & -- & -- & -- & $0.46 \pm 0.16$ & -- \\
\hline
\end{tabular}


Table 4. Consumptions of alloying elements in the $\alpha$-Chinese script intermetallics and their supersaturation levels in the $\mathrm{Al}$ matrix (wt\%).

\begin{tabular}{ccccccc}
\hline \multirow{2}{*}{ Alloy } & \multicolumn{1}{c}{$\mathrm{Mn}$} & $\mathrm{Si}$ & $\mathrm{Fe}$ & $\mathrm{Cr}$ & $\mathrm{V}$ & $\mathrm{Mo}$ \\
\cline { 2 - 6 } & \multicolumn{7}{c}{ Consumptions in $\alpha$-Chinese script intermetallics } & & \\
\hline B & 0.297 & 0.213 & 0.247 & 0.000 & 0.000 & 0.000 \\
C & 0.381 & 0.309 & 0.294 & 0.047 & 0.000 & 0.000 \\
D & 0.426 & 0.303 & 0.295 & 0.000 & 0.017 & 0.000 \\
E & 0.477 & 0.367 & 0.312 & 0.065 & 0.027 & 0.000 \\
F & 0.377 & 0.303 & 0.301 & 0.000 & 0.000 & 0.050 \\
\hline \multicolumn{7}{c}{ Supersaturation levels in the Al matrix } \\
B & 0.743 & 0.507 & 0.043 & 0.000 & 0.000 & 0.000 \\
C & 0.619 & 0.451 & 0.006 & 0.133 & 0.000 & 0.000 \\
D & 0.614 & 0.417 & 0.005 & 0.000 & 0.233 & 0.000 \\
E & 0.573 & 0.313 & 0.008 & 0.155 & 0.223 & 0.000 \\
F & 0.633 & 0.367 & 0.009 & 0.000 & 0.000 & 0.250 \\
\hline
\end{tabular}

Table 5. Alloying element levels (wt\%) within the $\mathrm{Al}$ dendrites of alloys $\mathrm{B}$ to $\mathrm{F}$ in the as-cast condition, as measured using EPMA-WDX analysis.

\begin{tabular}{cccccc}
\hline \multirow{2}{*}{ Alloy } & \multicolumn{5}{c}{ Element } \\
\cline { 2 - 6 } & $\mathrm{Mn}$ & $\mathrm{Si}$ & $\mathrm{Cr}$ & $\mathrm{V}$ & Mo \\
\hline B & $0.880 \pm 0.037$ & $0.310 \pm 0.050$ & 0.000 & 0.000 & 0.000 \\
C & $0.773 \pm 0.056$ & $0.254 \pm 0.060$ & $0.208 \pm 0.034$ & 0.000 & 0.000 \\
D & $0.769 \pm 0.054$ & $0.207 \pm 0.071$ & 0.000 & $0.374 \pm 0.073$ & 0.000 \\
E & $0.660 \pm 0.032$ & $0.168 \pm 0.022$ & $0.182 \pm 0.042$ & $0.201 \pm 0.058$ & 0.000 \\
F & $0.777 \pm 0.047$ & $0.171 \pm 0.018$ & 0.000 & 0.000 & $0.340 \pm 0.050$ \\
\hline
\end{tabular}

Table 6. Characteristics of dispersoids formed in the studied alloys.

\begin{tabular}{cccccc}
\hline Dispersoid characteristics & \multicolumn{5}{c}{ Alloy } \\
\cline { 2 - 6 } & $\mathrm{B}$ & $\mathrm{C}$ & $\mathrm{D}$ & $\mathrm{E}$ & $\mathrm{F}$ \\
\hline $\begin{array}{c}\text { Equivalent diameter } \\
(\overline{\mathrm{D}}), \mathrm{nm}\end{array}$ & $43.22 \pm 3.34$ & $36.62 \pm 4.97$ & $38.15 \pm 4.86$ & $30.44 \pm 2.78$ & $40.50 \pm 2.18$ \\
\hline $\begin{array}{c}\text { Volume fraction } \\
\left(V_{\mathrm{v}}\right), \%\end{array}$ & $1.85 \pm 0.32$ & $1.22 \pm 0.23$ & $1.32 \pm 0.21$ & $1.07 \pm 0.26$ & $1.24 \pm 0.15$ \\
\hline $\begin{array}{c}\text { Dispersoid free zone } \\
(\mathrm{DFZ}), \%\end{array}$ & $14.97 \pm 1.08$ & $21.43 \pm 1.79$ & $22.31 \pm 2.43$ & $23.57 \pm 2.36$ & $17.43 \pm 1.72$ \\
\hline
\end{tabular}


Table 7. Contributions of the dispersoids to the yield strengths of alloys B to $\mathrm{F}$ and the increases in the measured yield strengths of these alloys in MPa at room temperature and $300{ }^{\circ} \mathrm{C}$.

\begin{tabular}{ccccc}
\hline \multirow{2}{*}{ Alloy } & \multicolumn{2}{c}{ At room temperature } & \multicolumn{2}{c}{ At $300{ }^{\circ} \mathrm{C}$} \\
\cline { 2 - 5 } & $\begin{array}{c}\text { Calculated YS } \\
\text { contribution of } \\
\text { dispersoids }\end{array}$ & $\begin{array}{c}\text { Measured yield } \\
\text { strength } \\
\text { increment }^{1}\end{array}$ & $\begin{array}{c}\text { Calculated YS } \\
\text { contribution of } \\
\text { dispersoids }\end{array}$ & $\begin{array}{c}\text { Measured yield } \\
\text { strength }^{\text {increment }}{ }^{1}\end{array}$ \\
\hline B & 48.1 & 56.4 & 37.0 & 44.5 \\
C & 44.3 & 59.1 & 34.1 & 46.1 \\
D & 44.7 & 64.0 & 34.4 & 47.6 \\
E & 47.7 & 62.0 & 36.7 & 44.3 \\
F & 41.4 & 59.9 & 31.9 & 43.2 \\
\hline
\end{tabular}

${ }^{1}$ It is the difference between the measured yield strengths of the given alloy and the base A alloy (Fig. 7). 

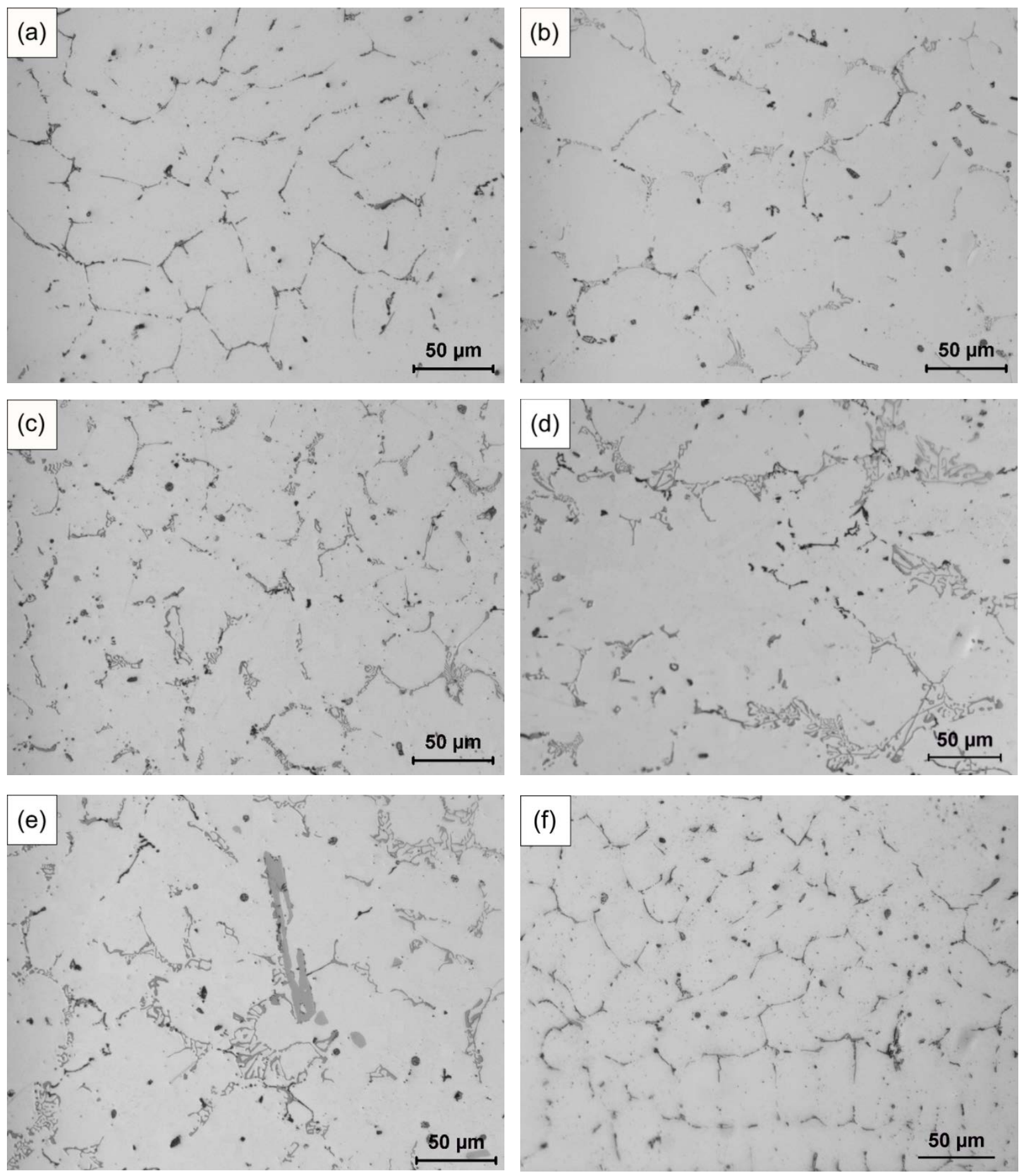

Fig. 1. Optical micrographs showing the as-cast microstructures of alloys (a) A, (b) B, (c) C, (d) D, (e) E, and (f) F. 

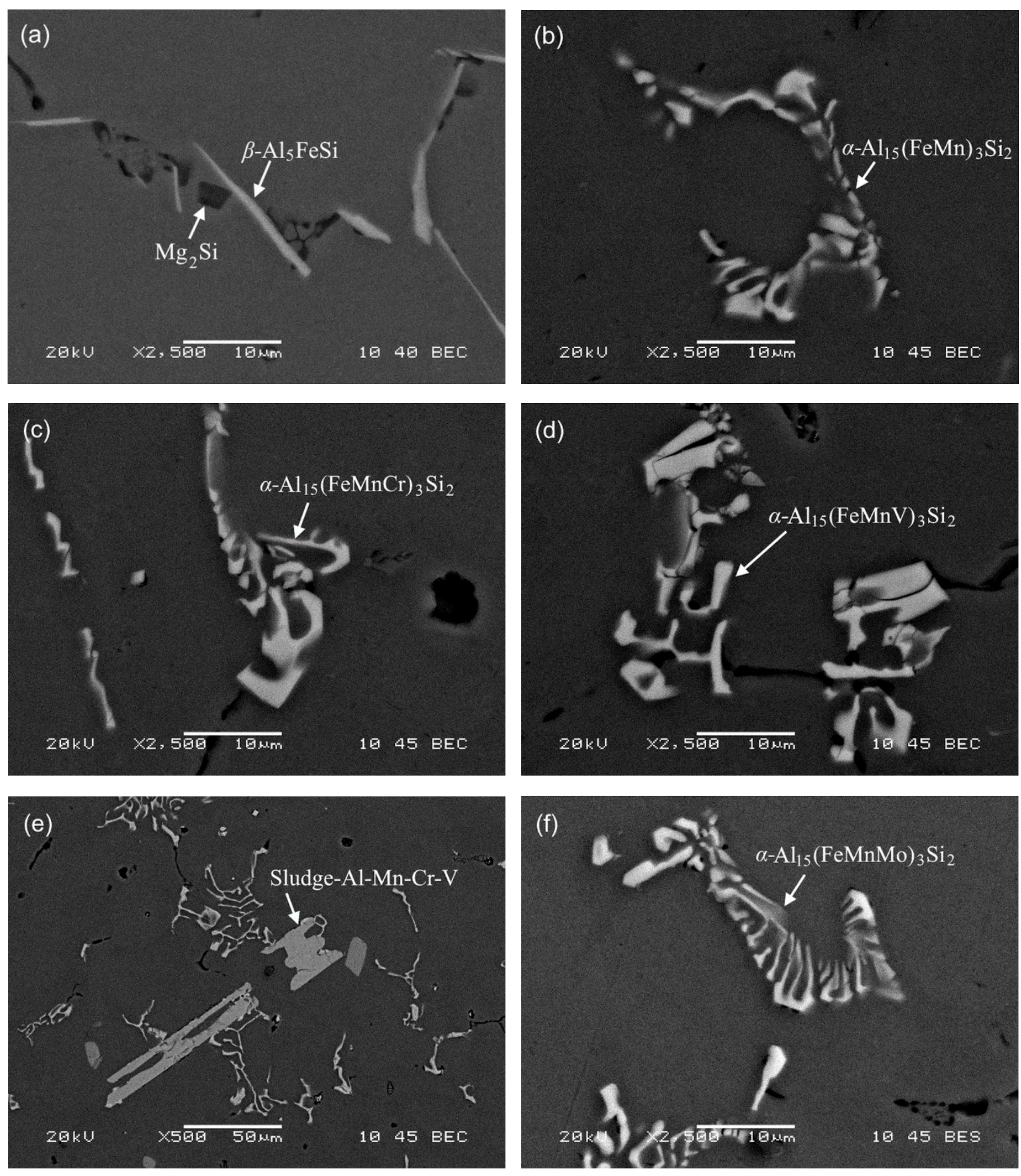

Fig. 2. SEM backscattered images showing intermetallic phases formed in alloys (a) A, (b) B, (c) C, (d) $\mathrm{D}$, (e) $\mathrm{E}$, and (f) $\mathrm{F}$ in the as-cast condition. 

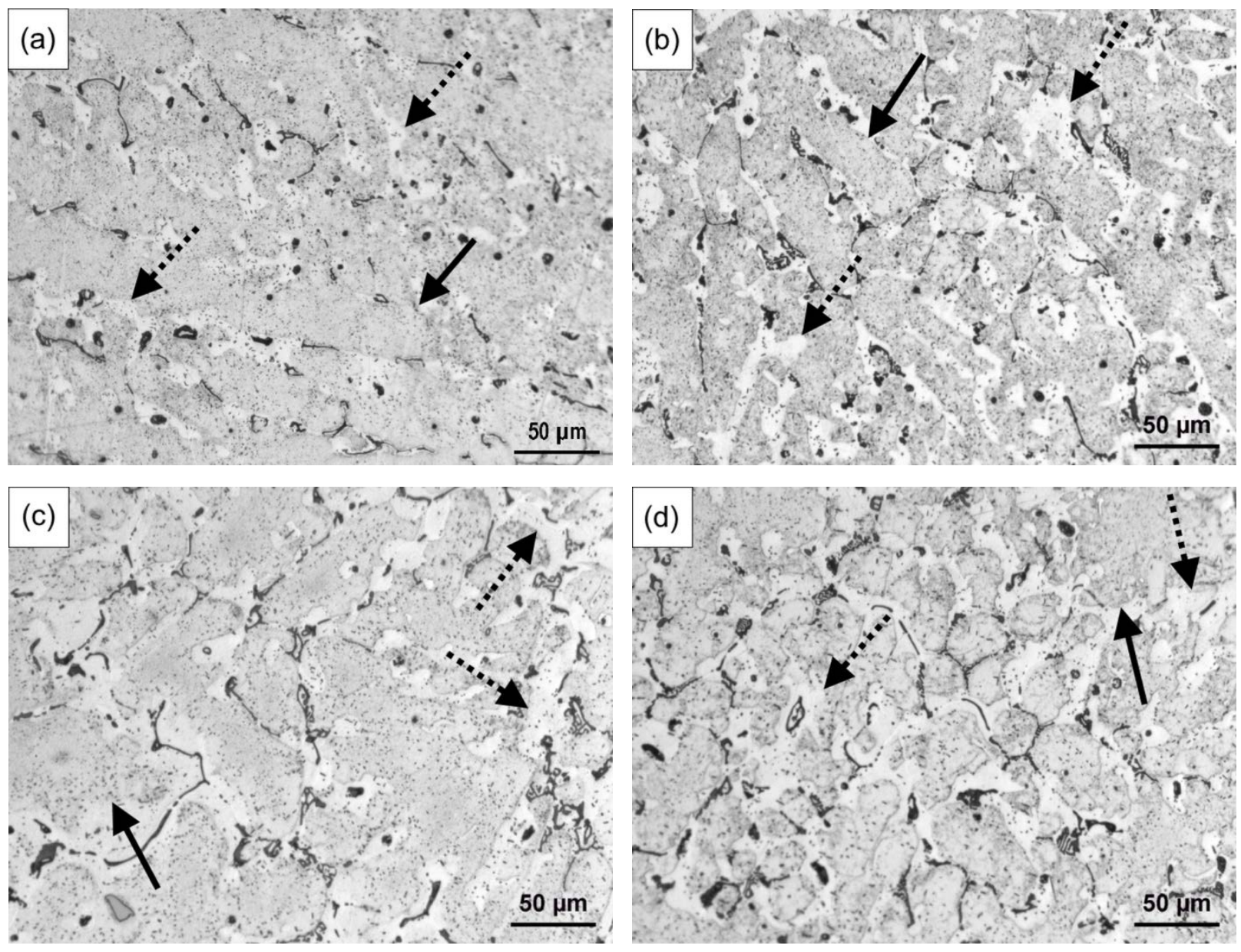

Fig. 3. Etched microstructures showing DZs and DFZs (indicated by solid and dotted arrows, respectively) in alloys (a) B, (b) C, (c) D, and (d) E in the homogenized condition. 

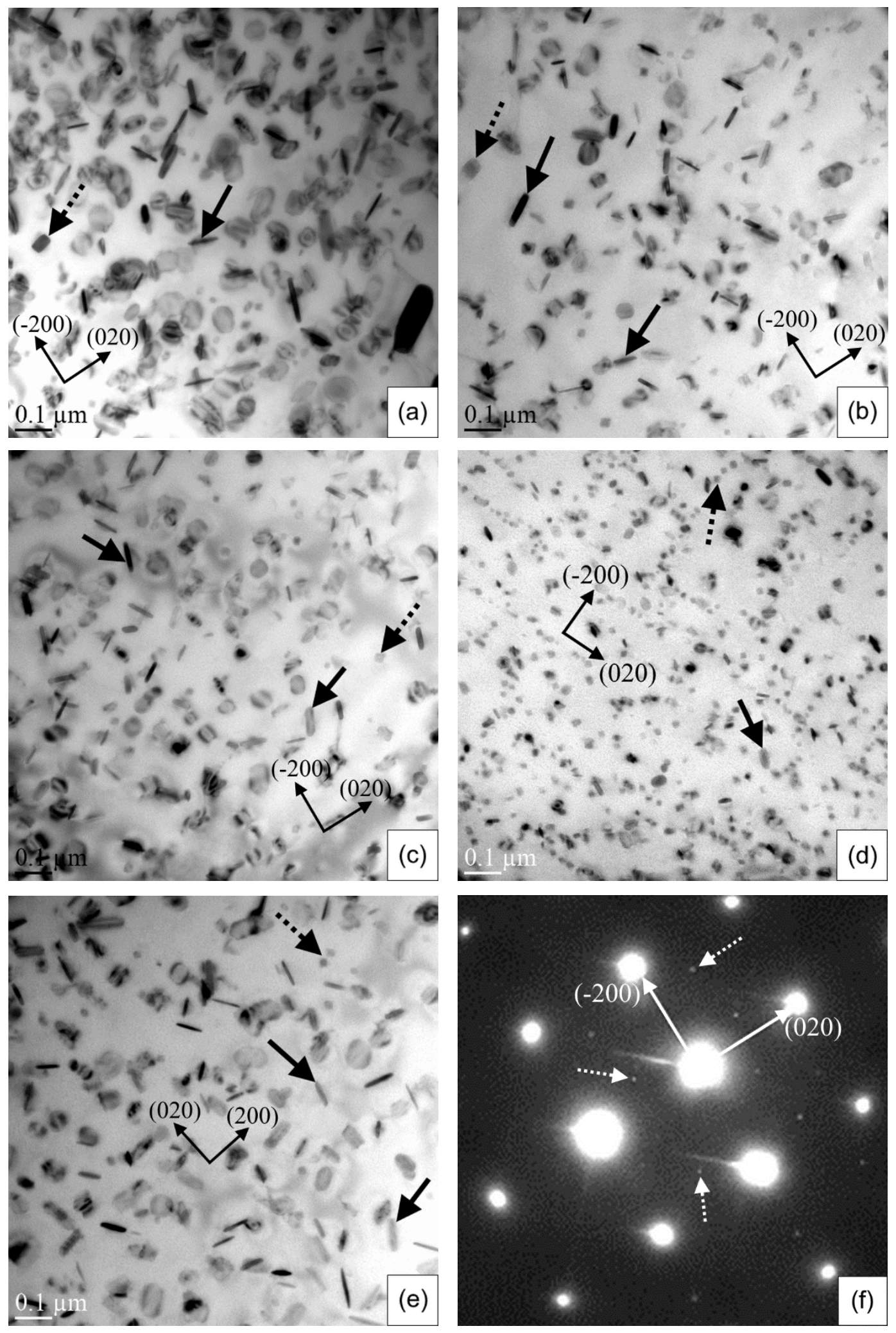

Fig. 4. (a) to (e) TEM bright-field images showing the dispersoids formed in alloys B to F, respectively, and (f) [001 $]_{\alpha}$ zone axis recorded SAEDP corresponding to the TEM bright-field image in (a). 

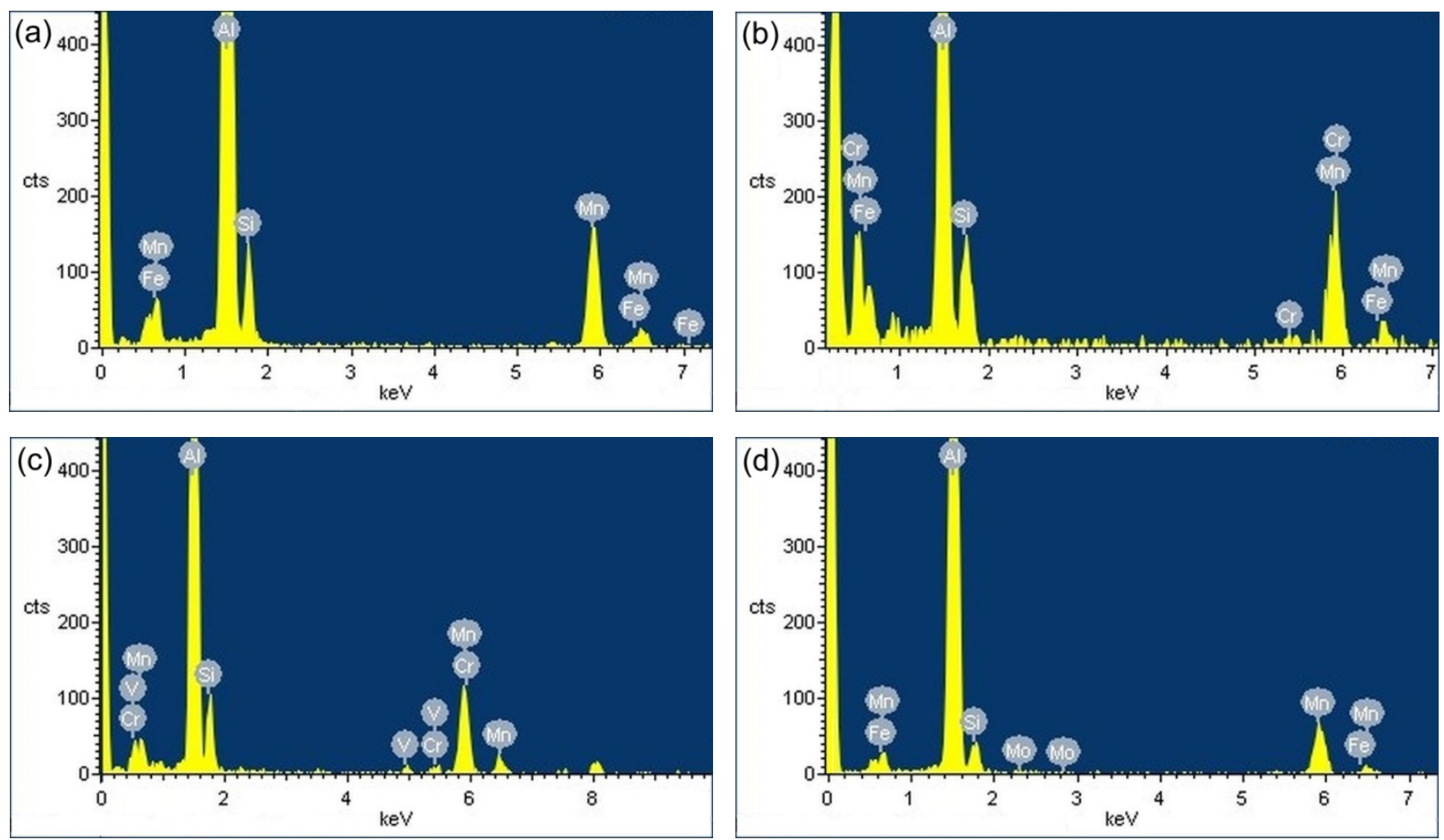

Fig. 5. TEM-EDS spectra showing the compositions of the dispersoids formed in alloys (a) B, (b) C, (c) E, and (d) F. 


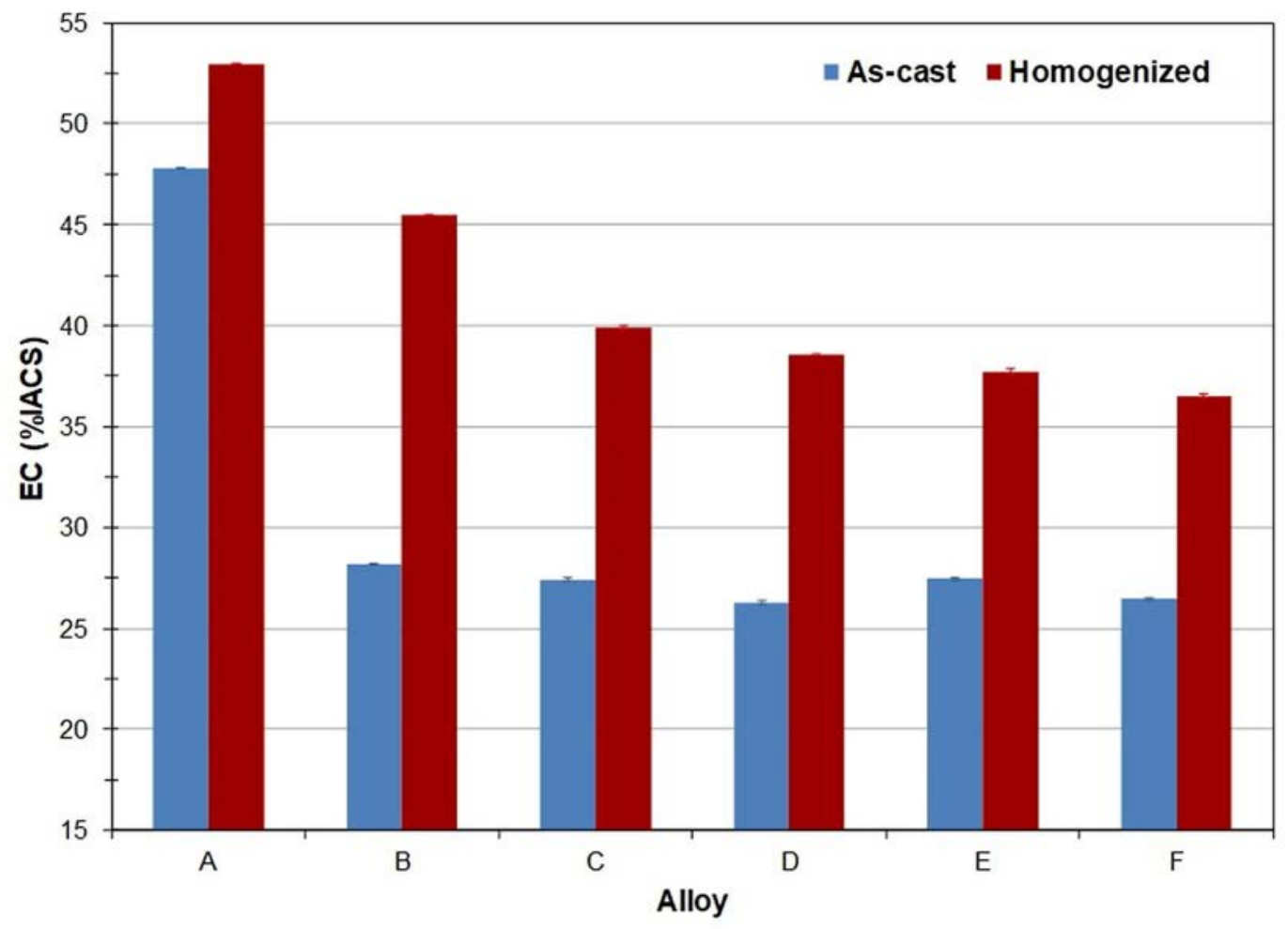

Fig. 6. Electrical conductivities (ECs) of the alloys prepared in this study in the as-cast and homogenized conditions.

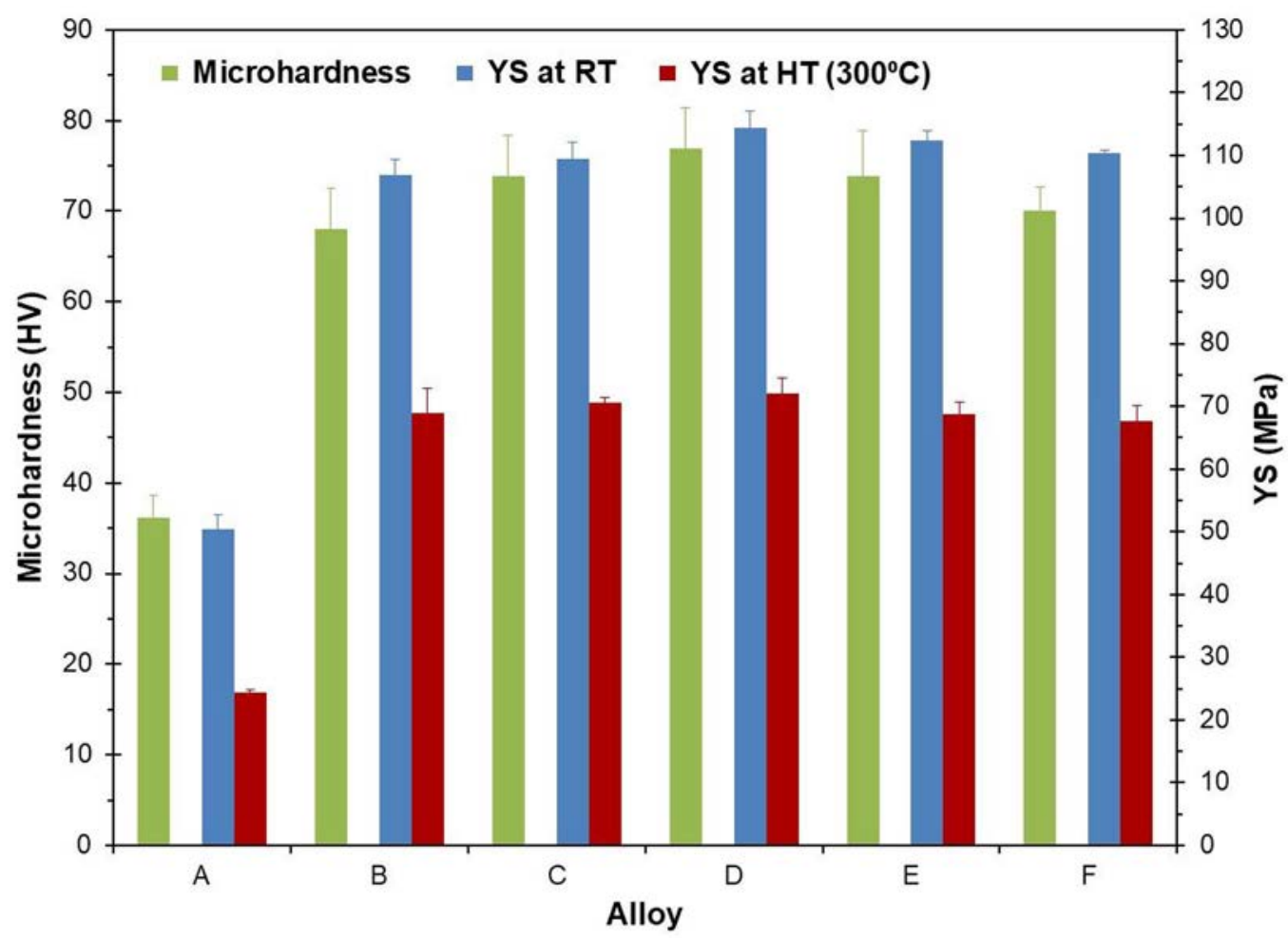

Fig. 7. Microhardness and compressive yield strengths of the alloys at room temperature and $300{ }^{\circ} \mathrm{C}$. 

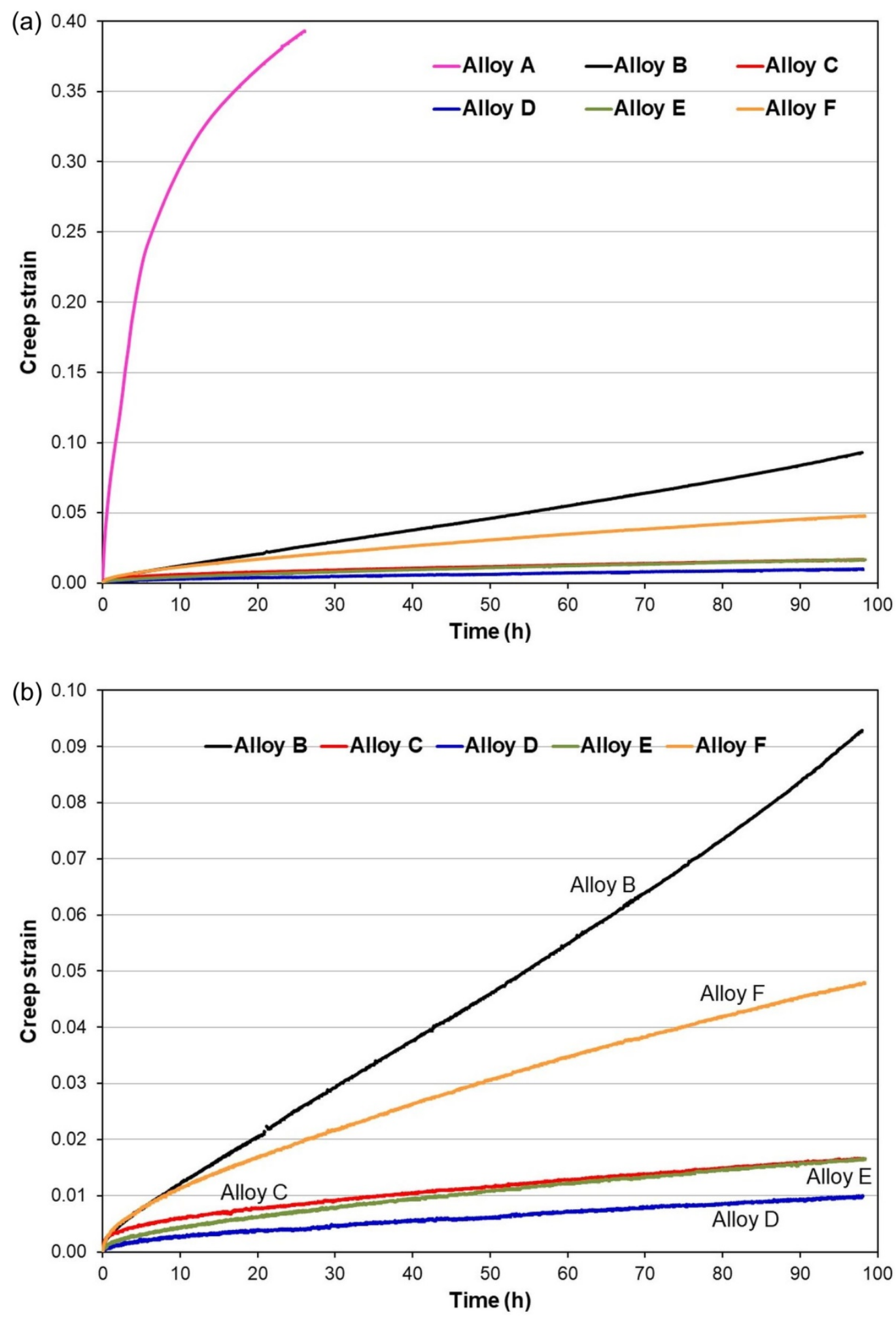

Fig. 8. Compressive creep curves of the alloys studied with two different strain ranges: (a) 0.00 to 0.40 and (b) 0.00 to 0.10 . The compressive creep load was approximately equal to 0.7 of the compressive yield strength at $300^{\circ} \mathrm{C}$. 


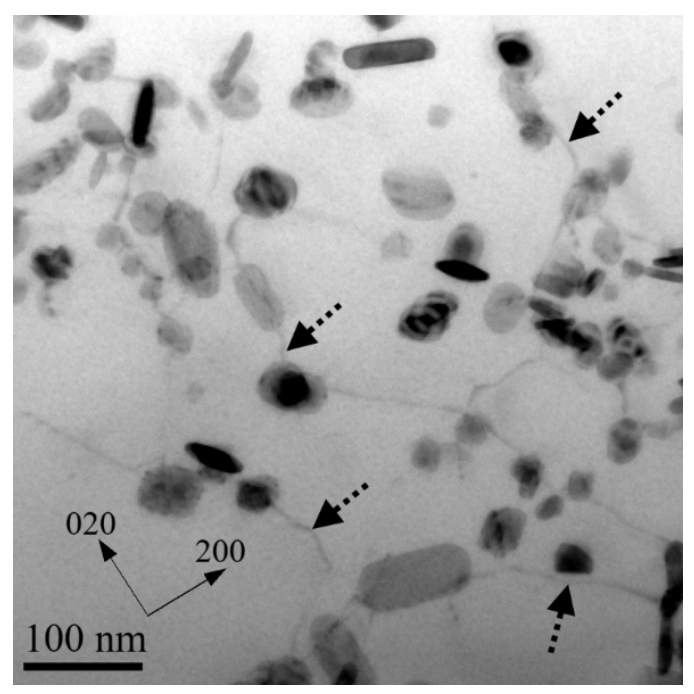

Fig. 9. TEM bright-field image obtained from the crept sample of alloy B. The dotted arrows indicate dispersoid-dislocation interactions. 